\title{
Pelatihan Pembuatan Salad Sayur Hidroponik dan Cara Pemasaran yang Tepat dalam E-Commerce
}

\author{
Juliana ${ }^{1}$ \\ Fakultas Pariwisata, Universitas Pelita Harapan,Tangerang \\ Juliana.stpph@uph.edu \\ Sandra Maleachi² \\ Fakultas Pariwisata, Universitas Pelita Harapan,Tangerang \\ Kevin Gustian Yulius ${ }^{3}$ \\ Fakultas Pariwisata, Universitas Pelita Harapan,Tangerang \\ Jimmy Situmorang 4 \\ Fakultas Pariwisata, Universitas Pelita Harapan,Tangerang
}

\begin{abstract}
Abstrak
Salad termasuk ragam makanan yang berdayaguna dibuat tetapi berlimpah dengan faedah. Makanan ini dikreasi dengan mengkombinasikan beragam jenis buah dan sayuran dan memperbanyak bumbu atau saus untuk memperbanyak selera. Karena dimakan mentah, komposisi nutrisi pada sayur-sayuran dan buah-buahan ini masih terpelihara, sehingga konsumen memperoleh faedahnya secara optimal. Salad dikonsumsi dari variasi buah dan sayuran sesuai selera.Ada salad khas buah yang disebut juga salad buah, salad khusus sayuran yang disebut salad sayuran, ataupun campuran keduanya. Dibandingkan salad sayur tentu salad buah mempunyai selera tersendiri yang berbeda karena buah-buahan sangat menonjol memiliki rasa yang lebih manis daripada sayuran. Salad sayuran merupakan salah satu makanan sehat namun masih jarang dikonsumsi oleh masyarakat, dikarenakan faktor utama dari sayuran yang mudah kering dan tidak segar sehingga baik konsumen maupun produsen tidak melakukan penyimpanan berlebih untuk bahan baku salad. Sejalan dengan masalah yang ditemukan maka PkM ini lebih memberikan suatu pengajaran bagaimana memanfaatkan sayuran hidroponik yang ada di Kampung Gerendeng Pulo untuk diolah menjadi salad yang nantinya dapat dikembangkan untuk menaikkan ekonomi masyarakatnya melalui penjualan dengan memanfaatkan ecommerce, tetapi sedikit pengetahuan yang dimiliki oleh masyarakat Kampung Gerendeng Pulo. Pola ajar dengan memberikan resep dan praktik lapangan pembuatan berbagai macam salad sayur dan pencampurannya dengan bahan lain seperti buah dan biji-bijian, serta mengenal jenis kemasan dan cara mengemas dengan baik lalu memasarkannya melalui e-commerce. Diharapkan masyarakat Kampung Gerendeng Pulo menjadi mengerti lebih lagi tentang bagaimana mengolah salad menjadi tahan lama serta dapat membuka peluang untuk menekuni bisnis makanan sehat.
\end{abstract}

Kata Kunci: salad, sayuran, buah, gerendeng pulo, e-commerce 


\begin{abstract}
Salad is a type of practical food that easily made and it is rich of benefits. This salad is usually made by mixing several kinds of fruits and vegetables (most fruits and vegetables are still raw) which later topped by seasoning or salad sauce to enhance its taste. Because most salad are consummed raw, the nutrition parts in vegetables and fruits are still intact, therefore, we could receive its nutrition optimally. Special salad made of fruits is called fruits salad, and special salad made of vegetables is called veggie salad, and there is even special made salad from the combination of those two, called mixed salad. Compare to vegetables salad, people would consume fruits salad more because normally fruits have dominant sweeter end taste compared to vegetables. Even though vegetables salad is considered healthy food, it is rarely consummed by people. One of main reasons that people rarely eat vegetable salad because it is easily dried and looked pale, therefore, most consumers and producers do not store much of vegetables. Thus, this community service is pointing out on teaching how to use the hydroponic vegetables in Kampung Gerendeng Pulo where later it can also benefited them through its sales by using e-commerce. The teaching method is given by giving several recipes and hands-on teaching of making varieties of salad. This involves introducing the right packaging for the product. The people from Kampung Gerendeng Pulo are expected to understand making durable salad and opening a chance to pursue healthy food business.
\end{abstract}

Keywords: salad, vegetables, fruits, gerendeng pulo, e-commerce

\title{
Pendahuluan
}

Pemerintahan Kota Tangerang terus menggalakkan program reboisasi dengan penanaman pohon. Salah satu penyebabnya adalah semakin bertambahnya koloni dan bangunan yang tidak menyisakan tempat untuk tanaman dan penghijauan. Keterbatasan lahan yang ada tidak menjadi penghambat untuk melaksanakan reboisasi di kawasan tinggal (koloni) padat penduduk seperti di Kampung Gerendeng Pulo, diawali dari Rumah Sehat yang asri dengan tumbuhan obat keluarga dan tumbuhan lainnya. Kampung Gerendeng Pulo merupakan kampung yang terletak ditengah kota Tangerang dan masuk kedalam wilayah Gerendeng. Kampung Gerendeng Pulo utamanya terletak di jalan Gerendeng Pulo dan mudah untuk ditemui. Program reboisasi di Kampung Gerendeng Pulo menghasilkan banyak hal yang bermanfaat seperti hasil tanaman hidroponik. Teknologi hidroponik yang sangat mudah untuk diimplementasikan dilakukan di Kampung Gerendeng Pulo dan dari tanaman itu pula timbul suatu kesadaran akan hidup yang sehat dan lebih baik. Warga Kampung Gerendeng Pulo berhasil membuat suasana komplek kawasan tinggal (koloni) yang kelihatan hijau oleh tumbuhan di kiri dan kanan jalan bahkan mural dengan kata-kata arif banyak ditemukan di sudut permukiman. Kampung Perilaku Hidup Bersih dan Sehat (PHBS) kelurahan Gerendeng Pulo, Kecamatan Karawaci terpilih menjadi salah satu lokasi penilaian lomba Hari Kesatuan Gerak PKK KB Kesehatan tingkat Provinsi Banten. Salah satu produk agraria yang berkemampuan untuk dibudidayakan yakni produk hortikultura. Hortikultura merupakan bagian dari sektor pertanian yang termasuk sayuran, buahbuahan, tanaman hias, dan biofarmaka. Komoditas hortikultura mempunyai nilai 
ekonomi yang sangat tinggi, sehingga usaha agribisnis hortikultura (buah, sayur, florikultura dan tanaman obat) dapat menjadi sumber pendapatan bagi masyarakat (Indriasti, 2013) . Salah satu produksi hortikultura yaitu sayuran, produk sayuran memegang peranan penting dalam pemuasan kebutuhan manusia khususnya dalam hal kecukupan pangan dan gizi yang dibutuhkan. Meningkatnya populasi penduduk, kesejahteraan masyarakat, serta pengetahuan masyarakat akan kesehatan maka akan berpengaruh terhadap peningkatan permintaan akan produk sayuran. Menurut Riskesdas 2013, saran untuk memakan sayur dan buah-buahan adalah minimal lima (5) porsi per hari, namun perbandingan kurang makan sayur dan buah di Indonesia sangat tinggi, yakini $93,60 \%$. Sepuluh pesan pedoman gizi seimbang di Indonesia juga menyarankan untuk banyak mengonsumsi sayur dan buah-buahan yang cukup. Dengan mengonsumsi sayur dan buah-buahan setiap hari dapat memperkecil resiko penyakit kronis seperti penyakit jantung coroner, beberapa jenis kanker (Jen Wen Hung Yee-Hwa Wu Chao-Hsing Yeh, 2004) serta mengurangi resiko obesitas (Heo et al., 2011) , dan mengurangi resiko stroke (Johnsen, S. P., Overvad, K., Stripp, C., Tjønneland, A., Husted, S. E., \& Sørensen, 2003). Dinyatakan bahwa konsumsi buah dan sayuran menguraikan manfaat kesehatan dari makan buah dan sayuran. Baru-baru ini, pesan berbasis norma sosial yang menggambarkan kebiasaan makan sehat orang lain telah terbukti meningkatkan asupan buah dan sayuran pada orang dewasa (Sharps \& Robinson, 2016). Mengonsumsi buah-buahan dapat mengurangi risiko diabetes dan mengurangi penyakit asma dan paru serta menurunkan risiko depresi, berkontribusi terhadap kepadatan mineral tulang yang lebih tingi pada anak-anak dan orang dewasa. (Mark L. Dreher, 2018) Menurut (Hu, Huang, Wang, Zhang, \& Qu, 2014) menyatakan bahwa mengonsumsi buah dan sayuran dapat mengurangi resiko stroke secara konsisten dan berkontribusi untuk perlindungan tubuh. Semakin meningkatnya pengetahuan ide dan teknologi di bidang pertanian saat ini, dalam mengusahakan sayuran ada beberapa media tanam yang dapat digunakan sebagai wadah tempat tumbuhnya sayuran diantaranya hidroponik, aeroponic dan aquaponic. Metode-metode tersebut dilakukan karena lahan pertanian juga yang semakin sempit (Herwibowo, 2015). Teknologi hidroponik adalah metode bercocok tanam yang menggunakan air, nutrisi dan oksigen, teknologi hidroponik memiliki banyak kegunaan dibandingkan dengan teknik bertanam secara tradisional. Keunggulan hidroponik antara lain ramah lingkungan, barang yang dihasilkan higienis, pertumbuhan tanaman lebih cepat, kualitas hasil tanaman dapat terjaga, dan kuantitas dapat lebih meningkat. Sayuran yang diproduksi dengan sistem hidroponik juga menjadi lebih sehat karena terbebas dari kontaminasi logam berat industry yang ada didalam tanah, segar dan tahan lama, serta mudah dicerna (Indriasti, 2013). .Sayuran yang dihasilkan dengan menggunakan teknologi hidroponik memiliki kualitas yang lebih baik dibandingkan sayuran sederhana. Sayuran hidroponik yang dihasilkan untuk dikonsumsi haruslah dapat dipastikan terdistribusi dengan baik kepada konsumen, khususnya konsumen dalam era modern saat ini banyak yang lebih memilih langsung makanan yang sehat dengan kategori tanpa dimasak terlebih dahulu. Makanan yang dapat langsung diolah dan dikonsumsi dari sayuran organik dengan dinikmati langusng biasanya dalam bentukan seperti lalapan atau salad. Salad merupakan variasi makanan yang 
sangat efisien dan efektif dibuat serta banyak akan manfaat. Makanan ini dibuat dengan cara mencampurkan berbagai jenis buah dan sayuran (yang sebagian dalam kondisi mentah) serta menambahkan bumbu atau saus untuk menambah cita rasanya. Makanan salad yang identik dengan kesehatan ini akan lebih baik lagi jika menggunakan sayur organik dan bagaimana salad itu diterima oleh konsumen akan sangat berpengaruh terhadap nilai jual makanan tersebut. Konsumen dalam hal ini lebih melihat pada kesegaran produk serta bentuk kemasan yang baik dan adanya informasi yang jelas dari makanan yang akan dikonsumsi. Pemahaman dari (Tjiptono \& Fandy, 2010) packaging termasuk metode yang berhubungan dengan pemrograman dan pembentukan tempat atau pelapis untuk suatu barang. Kemasan termasuk aktivitas peletakan produk ke dalam wadah, tempat, isi, atau sejenisnya yang terbuat dari timah, kayu, kertas, gelas, besi, plastic, kain, karton, atau material lainnya yang dilakukan oleh produsen atau pemasar untuk disampaikan kepada konsumen. Kemasan bukan hanya terdiri atas pelayanan tetapi juga sebagai salesman dan pengantar kepercayaan, dimana suatu kemasan termasuk penglihatan akhir dari konsumen yang dapat dipercaya. Menurut (Kotler \& Keller, 2009) kemasan yang baik dapat membangun ekuitas merek dan mendorong penjualan.

Kemasan terdiri dari tiga hal, yaitu merek, kemasan itu sendiri, dan label. Adapun tiga alasan utama untuk melakukan pengemasan adalah pertama, kemasan memenuhi syarat keamanan dan kemanfaatan. Kemasaan melindungi produk dalam perjalannya dari produsen ke konsumen. Produk-produk yang dikemas biasanya lebih bersih, menarik, dan tahan terhadap kerusakan yang disebabkan oleh cuaca. Kedua, kemasan dapat melaksanakan program pemasaran. Melalui kemasan, identifikasi produk menjadi lebih efektif dan dengan sendirinya mencegah pertukaran oleh produk pesaing. Kemasan merupakan satu-satunya cara perusahaan membedakan produknya. Ketiga, kemasan merupakan suatu cara untuk meningkatkan laba perusahaan. Oleh karena itu, perusahaan harus membuat kemasan semenarik mungkin agar dapat memikat dan menarik perhatian konsumen. Selain itu, kemasan juga dapat mengurangi kemungkinan kerusakan barang dan kemudahan dalam pengiriman. E-commerce merupakan kegiatan bisnis yang dilaksanakan secara elektronik via suatu jaringan internet dan computer atau kegiatan jual beli barang atau jasa melalui jalur komunikasi digital. Menurut (Majdah Zawawi, 2016) menyatakan bahwa e-commerce sangat mendukung pemasaran di bidang manufaktur untuk mendapatkan penghasilan karena dapat mengubah layanan. E-Commerce merupakan tindakan dukungan untuk memberikan informasi dan referensi tentang produk pertanian, pemasaran dan industri manufaktur terutama iklan di media sosial.

Pengabdian masyarakat yang telah dilakukan ini lebih mengutamakan pada pengajaran bagaimana mengolah sayuran hidroponik yang sudah berhasil ditanam menjadi suatu kreasi berbagai macam salad dan mencari faktor apa yang membuat konsumen membeli produk tersebut, faktor lain yang diajarkan adalah membuat kemasan dan label yang baik kemudian melakukan pemasaran yang tepat dengan mengikuti tren perkembangan pasar. Selain itu, informasi produk dari mulai produk sayur yang ditanam sampai dengan diolah menjadi kreasi salad dengan tambahan buah ataupun sayur lainnya akan sangat membantu dalam memasarkan dan 
diharapkan produk tersebut dapat bersaing dengan produk makan sehat lainnya. Berdasarkan uraian pendahuluan di atas, maka tim pengabdian kepada masyarakat melakukan observasi dan mendapatkan masyarakat pada era modern ini dihadapkan pada banyaknya pilihan makanan dan rasa yang sangat beragam, tetapi banyak masyarakat lebih memilih makanan praktik dimana masyarakat tidak perlu mencoba makanan lain dan memilih makanan yang sudah dikenal serta mudah didapatkan. Dalam keperluan sehari-hari segala kegiatan yang dijalani oleh setiap orang. Kegiatan yang semakin padat, membuat banyak orang memerlukan input makanan tambahan yang berguna untuk kesehatan tubuh. Masyarakat saat ini berusaha mengonsumsi makanan sehat agar menjadi terbiasa dan kesehatan badan terjaga. Hal itu dilakukan dengan memilih makanan alami dan dalam kondisi yang segar serta tanpa bahan pengawet. Salah satu makanan sehat yang aman dikonsumsi adalah salad, baik salad sayuran atau buah-buahan.

Salad buah adalah makanan alternatif yang menyehatkan, bahkan bisa mencegah dan mengobati beberapa jenis penyakit. Sayuran dan buah dalam salad kaya akan nutrisi, kandungan gizi, mengandung serat tinggi, juga mengandung berbagai vitamin dan mineral yang sangat berguna bagi kesehatan tubuh. Konsumen sering tidak mengecamkan, semangkuk kecil salad buah dengan komposisi tepat, akan sangat berguna bagi kesegaran tubuh. Salad memberikan kepada tubuh begitu banyak serat yang pada gilirannya akan menurunkan kolesterol dan mengurangi sembelit. Salad yang dibuat menggunakan bahan sayuran hidroponik akan menghasilkan nilai lebih untuk dikonsumsi. Kampung Gerendeng Pulo memiliki bahan baku yang dapat digunakan untuk pembuatan salad, tetapi kekurangan akan pengetahuan dan informasi akan makanan olahan salad membuat warganya tidak membuat makanan sehat tersebut. Hal lain yang meyebabkan kurangnya pengetahuan akan membuat salad adalah salad itu sendiri bukan merupakan makanan asli Indonesia dan masih banyak masyarakat yang kurang mengetahui sayuran jika diolah dapat menjadi salad yang makanan tersebut itu dapat menghasilkan cita rasa yang berbeda dan membuat orang mau dan akan terus mengonsumsinya. Pelatihan ini telah dilakukan untuk memenuhi penambahan pengetahuan dan informasi pada warga Kampung Gerendeng Pulo di Tangerang, dimana masyarakat diberi pelatihan membuat salad yang baik dan hasilnya dapat dijual dan menambah pendapatan rumah tangga maupun untuk keseluruhan warga Kampung Gerendeng Pulo. Hasil pelatihan ini pun mengajarkan beberapa resep salad yang tadinya sekedar dikonsumsi dengan cara mentah seperti lalapan menjadi cita rasa yang lebih modern dan sehat. Harapan setelah dilakukannya PkM ini adalah penambahan pengetahuan dan informasi mengenai pembuatan beragam salad, serta pemasarannya melalui e-commerce dengan pemanfaatan hasil tanaman hidroponik yang ditanam di Kampung Gerendeng Pulo. Pelatihan kepada masyarakat, khususnya ibu rumah tangga yang mengikuti pelatihan ini telah memiliki pengetahuan dan informasi yang mumpuni. Pelatihan dan presentasi pembekalan pemasaran dalam bentuk $\mathrm{PkM}$ juga sebagai dasar untuk mengembangkan usaha bagi masyarakat Kampung Gerendeng Pulo, Tangerang. Bagi pemerintah daerah setempat, dengan adanya pelatihan ini, dapat dijadikan sebagai sentral infromasi dalam membuat kebijakan dan pembinaan usaha kecil 
apabila produk yang telah diajarkan tersebut dapat diterapkan dengan baik di Kampung Gerendeng Pulo, Tangerang. Hasil pelatihan ini secara tidak langsung telah memberikan manfaat dan referensi bagi masyarakat sekitar untuk mengembangkan dan mempelajari lebih lanjut tentang usaha sayuran hidroponik serta cara pemasarannya menggunakan e-commerce.

\section{Metode}

Pelaksanaan telah dilakukan dengan dua (2) tahapan, yaitu tahapan pertama, adalah melakukan pengajaran dan pelatihan dengan metode praktik langsung dan dilakukan secara Bersama, serta memberikan informasi-informasi yang sudah disiapkan dalam bentuk modul fotokopi. Memberikan pengajaran kepada masyarakat Kampung Gerendeng Pulo khususnya anggota PKK tentang cara membuat variasi salad sayuran organik.Berdasarkan permasalahan yang dihadapi oleh Kampung Gerendeng Pulo maka solusi yang dapat ditawarkan merupakan

1. Pengajaran tentang makanan salad serta penyimpanan dan kesegaran kemasan.

2. Memberikan pengetahuan mengenai kemasan dan label yang harus digunakan untuk sayuran dan makanan segar.

3. Mengajarkan penggunaan e-commerce dalam kepentingan pemasaran produk salad dan pariwisata Kampung Gerendeng Pulo, Tangerang. Pengajaran cara pemasaran yang tepat menggunakan e-commerce dengan cara memilih beberapa orang dari peserta yang mampu atau bisa menggunakan perangkat komunikasi elektronik dengan baik, kemudian diajarkan secara Bersama dan orang yang terpilih telah menjadi mentor peserta yang lain.

4. Monitor telah dilakukan empat minggu dan sepuluh minggu setelah kegiatan pelatihan dengan hasil materi yang telah diberikan telah digunakan sesuai dengan hasil yang diharapkan.

5. Masyarakat dapat mempersiapkan diri untuk era pemasaran digital transformation 4.0

\section{Hasil dan Pembahasan}

Kegiatan pengabdian kepada masayarakat ini dilaksanakan berjalan dengan susunan acara yang telah ditetapkan. Peserta belajar cara membuat salad sayur hidopronik dengan lima (5) macam salad sayur hidroponik beserta panitia dan sebagian anggota tersebar ke lima (5) meja pelatihan yang telah dipersiapkan untuk menjadi penyelia bila ada peserta yang butuh pertolongan atau informasi tambahan. Setelah selesai membuat produk, panitia mengajarkan penempatan salad sayuran hidroponik kedalam wadah plastik dan mengajarkan membuat label dan cara penyimpanannya di lemari pendingin. Setelah mengerti, peserta dapat mencicipi hasil pelatihan tersebut. Selanjutnya, panitia memilih beberapa peserta untuk dilatih cara pemasaran yang tepat melalui e-commerce. Banyak peserta yang sudah mempunyai wadah media social, tetapi belum banyak yang mengetahui cara pemakaiannya untuk tujuan komersil, dengan itu panitia memberikan pengetahuan mengenai cara pemasaran produk menggunakan e-commere serta meminta peserta untuk mengisi kuesioner yang sudah panitia persiapkan dengan menggunakan skala likert 1 
(sangat tidak setuju), 2 (agak tidak setuju), 3 (tidak setuju), 4 (agak setuju), 5 (setuju), 6 (sangat setuju) terhadap 20 responden. Setelah melakukan pelatihan secara langsung maupun pemberian informasi tentang pemasaran menggunakan ecommerce, hasil yang didapat melalui pengumpulan kuesioner sangat baik. Mendapatkan respon yang baik dalam persiapan dan relevansi pengajaran terhadap kebutuhan masyarakat Kampung Gerendeng Pulo, Tangerang. Pemberian materi dan pengajaran dinilai baik dan didalam praktik kerja kelompok, pelatihan dan panduan pengajaran yang dipersiapkan dinilai sangat baik. Kerja kelompok sangatlah efektif dimana didalam pengajarannya, peserta mengikuti langkah demi langkah dalam pembuatannya dengan sangat kooperatif. Sebagai penutup, masyarakat Kampung Gerendeng Pulo, Tangerang, merasa pelatihan ini membuat masyarakat termotivasi untuk mengaplikasikannya dalam kehidupan sehari-hari. Adapun keinginan masyarakat Kampung Gerendeng Pulo, Tangerang selalu memberikan pelatihan lanjutan ataupun tambahan untuk membantu penambahan pengetahuan serta skill dan taraf hidup masyarakat

Hasil evaluasi peserta pada kegiatan ditampilkan pada deskripsi dibawah ini

Parameter pertama mengenai materi terorganisasi dengan baik dan mudah dipahami seluruh responden menanggapi sangat setuju sebesar 14 responden $(70 \%)$ dan sebesar 6 responden $(30 \%)$ memberikan tanggapan setuju. Parameter kedua responden memberikan tanggapan sangat setuju sebanyak 10 responden $(50 \%)$ dan sebanyak 10 responden $(50 \%)$ memberikan tanggapan setuju. Parameter ketiga mengenai pemateri sangat memahami materi yang dipresentasikan seluruh responden memberikan tanggapan sangat setuju sebanyak 13 responden $(65 \%)$ dan sebanyak 7 responden $(35 \%)$ memberikan tanggapan setuju. Parameter keempat mengenai alokasi waktu penyampaian materi mencukupi seluruh responden menanggapi sangat setuju sebanyak 10 responden $(50 \%)$ dan sebesar 10 responden (50\%) menanggapi setuju. Parameter kelima responden menanggapi sangat setuju sebanyak 13 responden (65\%) dan sebanyak 7 responden (35\%) menanggapi setuju. Parameter keenam mengenai fasilitas pelatihan membantu Anda dalam memahami materi yang disampaikan oleh pemateri seluruh responden menanggapi sangat setuju sebanyak 11 responden (55\%) dan sebanyak 9 responden $(45 \%)$ menanggapi setuju. Parameter ketujuh mengenai alokasi waktu untuk diskusi mencukupi untuk menambah / memperkuat pemahaman seluruh responden menanggapi sangat setuju sebanyak 8 responden (40\%) dan sebanyak 12 responden (60\%) memberikan tanggapan setuju. Parameter kedelapan mengenai pemateri memberikan jawaban terhadap pertanyaan peserta dengan baik seluruh responden memberikan jawaban sangat setuju sebanyak 10 responden (50\%) dan sebanyak 10 responden (50\%) memberikan jawaban setuju. Parameter kesembilan mengenai secara keseluruhan diskusi/tanya-jawab telah sangat membantu meningkatkan pemahaman peserta seluruh responden menanggapi sangat setuju sebanyak 8 responden $(40 \%)$ dan sebanyak 12 responden $(60 \%)$ memberikan jawaban setuju. Parameter 10 mengenai setelah mengikuti pelatihan ini Anda memahami cara membuat salad sayur hidroponik seluruh responden memberikan tanggapan sangat setuju sebanyak 10 responden (50\%) dan sebanyak 10 responden memberikan tanggapan setuju (50\%). Parameter 11 mengenai Panduan disusun dengan baik dan mudah dimengerti 
seluruh responden menanggapi sangat setuju sebanyak 10 responden $(50 \%)$ dan sebanyak 10 responden (50\%) memberikan tanggapan setuju. Parameter 12 mengenai Fasilitator telah memfasilitasi kerja kelompok dengan baik seluruh responden menanggapi sangat setuju sebanyak 10 responden (50\%) dan sebanyak 9 responden $(45 \%)$ menanggapi setuju serta 1 responden (5\%) memberikan tanggapan agak setuju. Parameter 13 mengenai Kerja praktik dalam kelompok adalah efektif untuk menyelesaikan tugas yang diberikan seluruh responden menanggapi sangat setuju sebanyak 10 responden (50\%) dan sebanyak 10 responden (50\%) menanggapi setuju. Parameter 14 mengenai Dengan panduan dan waktu yang disediakan serta bantuan fasilitator maka praktik dapat berjalan dengan baik seluruh responden menanggapi sangat setuju sebanyak 10 responden $(50 \%)$ dan sebanyak 10 responden $(50 \%)$ menanggapi setuju. Parameter 15 responden menanggapi sangat setuju sebesar 12 responden $(60 \%)$ dan sebesar 5 responden $(25 \%)$ menanggapi setuju serta 3 responden $(15 \%)$ menanggapi agak setuju

\section{Simpulan dan Rekomendasi}

Terdapat beberapa simpulan yang dapat ditarik dari kegiatan Pengabdian kepada Masyarakat yang telah dilakukan di Kampung Gerendeng Pulo, Tangerang kegiatan ini berhasil memberikan pengetahuan kepada masyarakat Kampung Gerendeng Pulo, Tangerang tentang pembuatan salad sayur hidroponik ,kegiatan ini berhasil memberikan informasi mengenai pemasarannya yang tepat melalui e-commerce serta kegiatan ini dinilai sesuai dengan kebutuhan yang diperlukan masyarakat Kampung Gerendeng Pulo dalam hal modal untuk menambah penghasilan bagi masyarakat Kampung Gerendeng Pulo. Keberlanjutan dari pengajaran yang dilakukan pada pengabdian kepada masyarakat ini diharapkan bahwa masyarakat Kampung Gerendeng Pulo, Tangerang dapat berjualan secara mandiri (berwirausaha) dengan pemberian pelatihan ini. Diharapkan, Kampung Gerendeng Pulo, Tangerang dapat menjadi sentra informasi dan pengetahuan dalam pengembangan usaha dari sayuran hidroponik. Panitia berkesempatan untuk berkunjung ke Kampung Gerendeng Pulo dan sudah mendapatkan informasi bahwa hasil pelatihan ini sudah disebarluaskan Degnan cara dalam kegiatan Rukun Warga setempat salad sayuran hidroponik ini sudah diperkenalkan didalam acara tersebut. Tim penulis mendapatkan beberapa saran dari peserta dalam hal seharusnya terdapat sesi khusus lagi mengenai cara membuka peluang usaha e-commerce, dan adanya keberlanjutan training serta memberikan tips untuk mengemas salad dalam bentuk yang menarik yang lainnya serta dapat mengembangkan tempat workshop agar lebih bagus lagi.

\section{Acknowledgements}

Tim Penulis mengucapkan banyak terima kasih kepada LPPM Universitas Pelita Harapan yang telah memberikan kesempatan melaksanakan kegiatan Pengabdian Kepada Masyarakat serta telah mendanai kegiatan ini (PM-027-FPar/V/2019) 


\section{Daftar Pustaka}

Heo, M., Kim, R. S., Wylie-Rosett, J., Allison, D. B., Heymsfield, S. B., \& Faith, M. S. (2011). Inverse Association Between Fruit And Vegetable Intake And Bmi Even After Controlling For Demographic, Socioeconomic And Lifestyle Factors. Obesity Facts. Https://Doi.Org/10.1159/000335279

Herwibowo, K. Dan N. S. B. (2015). Hidroponik Portabel. Jakarta: Penebar Swadaya.

Hu, D., Huang, J., Wang, Y., Zhang, D., \& Qu, Y. (2014). Fruits And Vegetables Consumption And Risk Of Stroke: A Meta-Analysis Of Prospective Cohort Studies. Stroke, 45(6), 1613-1619. Https://Doi.Org/10.1161/Strokeaha.114.004836

Indriasti, R. (2013). Analisis Usaha Sayuran Hidroponik Pada Pt Kebun Sayur Segar Kabupaten Bogor. 4.

Jen Wen Hung Yee,Hwa Wu Chao,Hsing Yeh. (2004). Comparing Stress Levels Of Parent Of Children With Cancer And Parents Of Children With Physical Disabilities. Psycho Oncology. 13(12), 893-903.

Johnsen, S. P., Overvad, K., Stripp, C., Tjønneland, A., Husted, S. E., \& Sørensen, H. T. (2003). Intake Of Fruit And Vegetable And The Risk Of Ischemic Stroke In A Cohort Of Danish Men And Women. The American Journal Of Clinical Nutrition., 78(1), 57-64. Https://Doi.Org/10.1093/Ajcn/78.1.57

Kotler, P., \& Keller, K. L. (2009). Manajemen Pemasaran Jilid 1 Edisi Ketigabelas. In Jakarta.

Majdah Zawawi, N. R. (2016). E-Commerce Sebagai Pendukung Pemasaran Perusahaanmajdah Zawawi1 And Noriah Ramli. (2016). E-Commerce Sebagai Pendukung Pemasaran Perusahaan. Jurnal Ilmiah “Integritas,” Vol.2 No.(May), 31-48. Jurnal Ilmiah "Integritas," Vol.2 No.(May), 31-48.

Mark L. Dreher. (2018). Whole Fruits And Fruit Fiber Emerging Health Effects. Nutrients, 10(12).

Sharps, M., \& Robinson, E. (2016). Encouraging Children To Eat More Fruit And Vegetables: Health Vs. Descriptive Social Norm-Based Messages. Appetite, 100, 18-25. Https://Doi.Org/10.1016/J.Appet.2016.01.031

Tjiptono, \& Fandy. (2010). Strategi Pemasaran, Edisi Kedua. Edisi I. Yogyakarta: Andi. 